\title{
Management of the Banana Cavendish Giant (AAA) in Postharvest for Increasing Its Shelf Life
}

\author{
Prisma Deyanira Zevada Reyes, Leopoldo Partida Ruvalcaba*, Vicente Álvarez Mares \\ Universidad Tecnológica de Culiacán, Carretera Culiacán-Imala km 2, Colonia Los Ángeles, en la Ciudad \\ Educadora del Saber, Culiacán de Rosales, México \\ Email: *parpolo@yahoo.com.mx
}

Received 20 October 2015; accepted 5 December 2015; published 10 December 2015

Copyright (C) 2015 by authors and OALib.

This work is licensed under the Creative Commons Attribution International License (CC BY).

http://creativecommons.org/licenses/by/4.0/

(c) (i) Open Access

\section{Abstract}

This research is conducted to determine if the shelf life of bananas increases when it is stored in closed polystyrene containers and placed in refrigerated camera with cool temperatures. Bananas were acquired when they were in greenness rates $1,2,3$ and 4 . In the refrigerator it is applied temperatures of $10^{\circ} \mathrm{C}-12^{\circ} \mathrm{C}$. By each maturity index $(1,2,3$ and 4$)$, the fruits were packaged in four containers (repeats), which were opened every five days to observe signs of sensory maturity. The response variables were the color, strength, taste and soluble solids. When bananas with maturity index 1 were stored in polystyrene containers closed, their shelf life was 21 days until the maturity index four showed, the shelf life of those ones with index 2 was 12 days until the maturity index 4 showed, but control who were confined in the bottom tray of the refrigerator were badly damaged. In bananas with maturity index 3 , the maturity index 4 was expressed five days later, while in control they observed signs of sensory maturity; however, through touch, manual pressure and sense of taste, it was felt that the firmness and taste of the flesh of control fruits was similar to those that they had packaged in polystyrene containers. The soluble solids increased from one to four, but diminished when they appeared sensory symptoms.

\section{Keywords}

Polystyrene Containers, Cool Temperaturas, Maturity Index, Sensory Maturity

Subject Areas: Plant Science

\section{Introduction}

De acuerdo con García et al. [1], el plátano (Musa paradisiaca) es una fruta de consumo generalizado en

${ }^{*}$ Corresponding author.

How to cite this paper: Reyes, P.D.Z., Ruvalcaba, L.P. and Mares, V.Á. (2015) Management of the Banana Cavendish Giant (AAA) in Postharvest for Increasing Its Shelf Life. Open Access Library Journal, 2: e2074.

http://dx.doi.org/10.4236/oalib.1102074 
México debido a su valor nutritivo, disponibilidad todo el año y su precio relativamente bajo. La producción promedio de 2000 a 2010 fue 2’111,800 t y los respectivos consumo total y per cápita fueron de 2’037,909 t y $19.7 \mathrm{~kg}$.

En México se cultivan aproximadamente 82,000 ha de plátano con una producción de 2.25 millones de toneladas, un rendimiento promedio de $29.2 \mathrm{t} \cdot \mathrm{ha}^{-1}$ y un valor de producción de 3978.2 millones de pesos. La mayor parte de la producción es comercializada principalmente en el mercado nacional. Las zonas productoras de plátano se ubican en las regiones tropicales y subtropicales de la costa del Golfo de México y en el litoral del Océano Pacífico, según SIACON-SAGARPA [2].

Artés [3]-[5] menciona que los consumidores de frutas y vegetales son cada vez más exigentes por la calidad de estos productos, no sólo la que tienen al ser empacados en origen, sino la que presentan en el momento de ser comprados y, más aún, al consumirse. Asimismo, que la solución idónea para preservar la calidad global (organoléptica, comercial, microbiológica y nutritiva) de los productos hortofrutícolas, y satisfacer las exigencias de los mercados internacionales, consiste en mejorar los tratamientos post-recolección.

Las técnicas de almacenamiento que se utilizan después de la cosecha y una vez que las frutas han sido empacadas para su comercialización en fresco, tienen el propósito de conservar la calidad de las mismas, teniendo en cuenta las condiciones ambientales adecuadas que permitan reducir la velocidad de los procesos vitales de estos productos, y disponer de ellos por períodos más prolongados que los normales, además ofrecer productos frescos a mercados distantes y reducir pérdidas durante su comercialización. Dentro de las técnicas más utilizadas para la conservación de frutas y hortalizas se encuentran la refrigeración, el uso de atmósferas controladas, uso de absorbentes de etileno, aplicación de películas cubrientes y aplicación exógena de fitorreguladores, indicadas por Parikh et al. [6]. El etileno es una hormona vegetal capaz de inducir la maduración de frutos, como el plátano, y que se genera a partir del aminoácido metionina, de acuerdo con Salisbury y Ross [7].

El almacenamiento en frío es la técnica más ampliamente utilizada para la conservación de frutas y hortalizas. Ésta se basa generalmente en la aplicación de ciertas temperaturas constantes a los frutos a conservar, siempre por encima del punto crítico para poder mantener sus cualidades organolépticas, nutritivas, etc.; durante un período de tiempo, que dependerá de la especie y variedad de que se trate. La conservación refrigerada bajo condiciones óptimas permite reducir las pérdidas cualitativas y cuantitativas debidas a desórdenes fisiológicos y podredumbres, retrasar la maduración y senescencia y prolongar la vida comercial de los productos hortofrutícolas en general, con calidad idónea para consumo en fresco o industrial, reportado por Artés [8] y Martínez [9], ya que de acuerdo con Vázquez et al. [10], la calidad y vida de anaquel de los frutos son factores importantes en la comercialización).

Guerra [11] considera que la respiración es el principal proceso de deterioro de los frutos, el mismo es atenuado por bajas temperaturas que logran disminuir la tasa respiratoria y la pérdida excesiva de agua, así como la velocidad de las reacciones bioquímicas y enzimáticas, y que la velocidad de respiración de un fruto se reduce a la mitad por cada $10^{\circ} \mathrm{C}$ en que disminuye la temperatura.

Por su parte, Ponce de León y Bósquez [12] consideran que en los frutos climatéricos como el mango, las temperaturas por encima de $40^{\circ} \mathrm{C}$ ocasionan un incremento en la actividad respiratoria; por el contrario, temperaturas menores de $13^{\circ} \mathrm{C}$ disminuyen su respiración y prolongan su vida de anaquel.

Las pérdidas de peso en los frutos se incrementan como consecuencia de la transpiración después de la cosecha y significa una disminución de la calidad y aceptabilidad, estas pérdidas suelen ocasionar mermas superiores al 5\% durante la comercialización, al $7 \%$ en la conservación frigorífica durante tres meses y posterior comercialización, reportado por Jiménez et al. [13].

Según Guerra [11], las condiciones de baja humedad provocan un incremento de la transpiración y por tanto una elevada pérdida de agua, lo que acelera la senescencia del fruto y una marcada pérdida de la calidad, tanto por la aparición de arrugas en la corteza como por el encogimiento y ablandamiento.

En la postcosecha, definida por Martínez et al. [14] como el periodo transcurrido desde que un producto es recolectado en su estado de madurez fisiológica hasta cuando es consumido en estado fresco, preparado o transformado industrialmente, los frutos evolucionan hacia la senescencia con pérdidas de calidad, ablandamiento, pérdida de acidez, vitamina $\mathrm{C}$ y características organolépticas (sabor y comestibilidad), pero según Martínez [9], la velocidad de reacción de los procesos metabólicos, que llevan a la pérdida de calidad, se duplica por cada $10^{\circ} \mathrm{C}$ de aumento de la temperatura, y en el rango de $0^{\circ} \mathrm{C}$ a $10^{\circ} \mathrm{C}$ puede llegar incluso a sextuplicarse. 
Tuset [15]; Saucedo y Arévalo [16] y Galán [17] refieren que la aplicación del frío disminuye los riesgos de aparición y desarrollo de ciertos agentes causantes de alteraciones como bacterias, hongos y levaduras. Aunque es importante señalar que puede disminuir la acción de los microorganismos, pero no inhibe la germinación de esporas de los patógenos que contaminan a las frutas. Sin embargo, Tuset [18] menciona que para reducir la incidencia de alteraciones patológicas durante el almacenamiento frigorífico, se deben tomar una serie de medidas higiénicas y profilácticas que van desde evitar el máximo de heridas y golpes en la recolección y transporte al almacén, pasando por una periódica limpieza y desinfección de las cajas de campo, línea de manipulación, almacén y cámaras frigoríficas, completándose con un tratamiento de fungicida aplicado a la propia fruta.

Martínez [9] ha observado que la temperatura constituye una de las variables más importante para la conservación de los productos hortofrutícolas. Siendo necesario el control de esta en los locales de almacenamiento, ya que a medida que disminuya la temperatura, se retarda la pérdida de calidad de los frutos. Sin embargo, existen limitaciones en cuanto a las temperaturas mínimas que pueden aplicarse en la frigoconservación. Dentro de estas limitaciones se encuentra la temperatura de congelación de los productos hortofrutícolas. Las frutas y vegetales para consumo en fresco, deben mantener activo su metabolismo, lo cual sólo puede conseguirse en fase líquida, por lo que no pueden ser sometidos a temperaturas inferiores a las de congelación que oscilan entre $0^{\circ} \mathrm{C}$ y $-1.5^{\circ} \mathrm{C}$. La segunda limitación es que algunos de los productos de origen tropical y subtropical presentan sensibilidad a las bajas temperaturas que se manifiesta por diferentes alteraciones y manchas en la piel, conocidas generalmente como lesión o daño por frío y que pueden causar una alta pérdida de calidad comercial.

Para evitar la deshidratación junto con el empleo de las temperaturas bajas se utilizan humedades relativas elevadas. La humedad relativa adecuada para un determinado producto dependerá de la relación superficie/ volumen de éste. A medida que esta relación es mayor, la transpiración también lo es. Un valor de la humedad relativa entre 85\% - 95\% es lo aconsejable para lograr el objetivo de la conservación, según Guerra [11].

Sheirs et al. [19] han indicado que el poliestireno expandido (PSE) es un polímero vinílico que estructuralmente es una cadena hidrocarbonada $\left(\mathrm{C}_{8} \mathrm{H}_{10}\right)_{\mathrm{n}}$, con un grupo fenilo $\left(\mathrm{C}_{6} \mathrm{H}_{6}\right)$ unido cada dos átomos de carbono. Asimismo, que el PSE es actualmente el cuarto plástico más consumido por detrás del polietileno, el polipropileno y el PCV y es, además, un residuo contaminante muy resistente a la acción del medio ambiente y del agua del mar.

Perdomo [20] señala que el poliestireno es un polímero de origen hidrocarbúrico, cuyo monómero base se conoce como estireno, el cual es un alqueno líquido constituido por un anillo bencénico unido en posición alílica al grupo etilénico $\left(\mathrm{C}_{6} \mathrm{H}_{5} \mathrm{CH}=\mathrm{CH}_{2}\right)$, y que a partir de este se obtiene el poliestireno, el cual para ser expandido se utiliza el método de suspensión en presencia de sustancias capaces de liberar gases durante el proceso de polimerización, produciendo la expansión de la masa polímera. Así, se obtiene el polímero expandido que popularmente se conoce como "anime", que sirve para envasar y embalar alimentos, y para el embalaje de artículos frágiles (equipos de TV, sonido, computadores, entre otros).

La ANAPE [21] refiere que el EPS es el acrónimo de Poliestireno Expandido (en su acepción en inglés). Este material más conocido como "corcho blanco", "poliespan” o "porexpan” es un material plástico celular, generalmente de color blanco, compuesto esencialmente de aire (hasta un 98\%) y se utiliza, por un lado en la construcción como aislante térmico y acústico o como material de aligeramiento de estructuras diversas, y, por otro, para el envasado y embalado de diversos productos y mercancías, además de otra multitud de aplicaciones que incluye los cascos de ciclistas y motoristas o envases especiales para el transporte de órganos destinados al trasplante.

Raimondo y Espejo [22] han observado que la calidad con que llegan las frutas al consumidor depende, en gran medida, del material del envase, y que dadas las exigencias cada vez mayores, tanto del mercado de exportación como del interno, es importante la adecuada selección del material para envase y embalaje. Además que el envase apropiado es el que soluciona problemas fisiológicos propios de la fruta, la protege prolongando su conservación y, al mismo tiempo, resalta su presentación sin incrementar considerablemente el precio del producto final.

Con el propósito de evitar experiencias desalentadoras cuando se exportan frutas porque éstas llegan en avanzado estado de madurez, aunado al hecho de que se dispone de pocos días [3] [4] para su comercialización, Sisler y Serek [23] y Blankenship [24] han reportado que se han encontrado alternativas de solución a través de productos que retardan el proceso de maduración y que mantienen la calidad de frutos, debido a la inhibición de 
la acción del etileno. Tal es el caso del 1-Metilciclopropeno (1-MCP) que bloquea la acción del etileno al unirse a su receptor en la célula, porque reduce la producción del etileno endógeno y protege a los frutos de la acción del etileno exógeno por cierto tiempo, pero según Blankenship y Dole [25], el 1-MCP puede incrementar, reducir o mantener inalterado el desarrollo de sólidos solubles en función de la especie.

De acuerdo con Osuna et al. [26], la combinación de tecnologías, como la de $300 \mathrm{~nL} \cdot \mathrm{L}^{-1}$ de 1Metilciclopropeno (1-MCP) con temperatura de $13^{\circ} \mathrm{C} \pm 1^{\circ} \mathrm{C}$ y $90 \% \pm 5 \%$ de humedad relativa (HR) en cámaras herméticas retrasan significativamente el proceso de maduración y pérdida de firmeza de frutos, para que puedan ser transportados a lugares distantes del lugar de producción.

El objetivo de la investigación fue determinar si se incrementa la vida de anaquel del plátano, cuando éste es almacenado dentro de contenedores de poliestireno cerrados y colocados en cámara refrigerada con temperatura fresca.

\section{Materiales Y Métodos}

Los experimentos se realizaron en el laboratorio de la Universidad Tecnológica de Culiacán, ubicada en el km 2 de la carretera Culiacán-Imala, en la Ciudad Educadora Sustentable del Saber, colonia Los Ángeles de Culiacán Rosales, Sinaloa, México, con coordenadas 2450'30"N y 10750'30"E, en altura de 58 msnm. Según García [27], el clima es $\mathrm{B}_{1} \mathrm{~S}_{1}$, semiárido con lluvias en verano e inverno y $670 \mathrm{~mm}$ de precipitación anual. La temperatura media anual es de $24^{\circ} \mathrm{C}$, con máximas de $41^{\circ} \mathrm{C}$ en verano y mínimas de $5^{\circ} \mathrm{C}$ en invierno, y humedad relativa promedio de $66.6 \%$ anual.

En la cámara de almacenamiento se aplicaron temperaturas de $10^{\circ} \mathrm{C}-12^{\circ} \mathrm{C}$ para tener de $8^{\circ} \mathrm{C}-10^{\circ} \mathrm{C}$ dentro de los contenedores de poliestireno, humedad relativa al $85 \%$ y renovación del aire conforme al funcionamiento del compresor del equipo de refrigeración; los plátanos fueron colectados en el Mercado de Abastos de Culiacán, Sinaloa, México, procurando que estuvieran en los índices de madurez 1, 2, 3 y 4, sin ser golpeados durante su colecta. Posteriormente fueron lavados con agua clorada a 5 ppm y secados manualmente, para no dar condiciones favorables a los hongos que suelen crecer y desarrollarse sobre éllos. Una vez secados fueron embazados en contenedores de poliestireno con capacidad de $10 \mathrm{~kg}$, mismos que fueron cerrados herméticamente y almacenados en la cámara cerrada y refrigerada.

Para evitar modificaciones de la atmósfera de almacenamiento dentro de los contenedores y fuera de los mismos dentro del refrigerador, debido a las interrupciones de la energía eléctrica que pudieran presentarse durante el desarrollo de los experimentos, se dispuso de un equipo automático generador de electricidad.

Por cada índice de madurez [1]-[4], los frutos fueron embazados en cuatro recipientes (repeticiones), los cuales fueron abiertos cada cinco días hasta observar signos de madurez sensorial o punto crítico en el que aún los frutos mantienen sus cualidades organolépticas (pequeñas manchas de color café en el epicarpio de los frutos); es decir, durante el tiempo de los experimentos los recipientes fueron abiertos de dos a cinco veces, según el índice de madurez utilizado. Las variables de respuesta fueron el color, firmeza, olor, sabor y sólidos solubles, estos últimos se midieron con refractómetro marca HANNA modelo HI96811.

\section{Resultados Y Discusión}

En la Figure 1 puede notarse que después que los plátanos con índice de madurez tres fueron confinados en contenedores de poliestireno cerrados dentro del refrigerador con temperatura de 12 - 14 y de $10^{\circ} \mathrm{C}-12^{\circ} \mathrm{C}$ dentro de los contenedores, éstos expresaron el color amarillo característico del índice de madurez cuatro, hasta los cinco días posteriores al envasado, sin que hasta esa fecha (10 de Marzo de 2015) se pusieran de manifiesto los síntomas típicos de la madurez organoléptica o sensorial, consistentes en manchas de color café sobre el epicarpio de los plátanos. Lo anterior indica que reacciones bioquímicas como la respiración fueron disminuidas por la atmósfera controlada (poco oxígeno y $\mathrm{CO}_{2}$, ambiente frío y nula circulación de aire) que se tuvo en los contenedores de poliestireno; es decir, en las condiciones de la atmósfera mencionada la concentración de oxígeno fue muy escasa y, en consecuencia, las generaciones de $\mathrm{CO}_{2}$ y etileno también fueron muy limitadas, ya que en condiciones cerradas, frías y al existir poco oxígeno, como lo mencionan Salisbury y Ross [7], las reacciones metabólicas de la metionina quizás también fueron muy escasas para generar el etileno, hormona que induce la maduración de frutos climatéricos como el plátano. Además, de acuerdo con Martínez et al. [14], en las frutas frías suele disminuir la respiración y, por tanto, el consumo de $\mathrm{O}_{2}$ y la producción de $\mathrm{CO}_{2}$.

Cuando los plátanos (testigo) fueron almacenados en la bandeja inferior del refrigerador (Figure 2), al final del- 


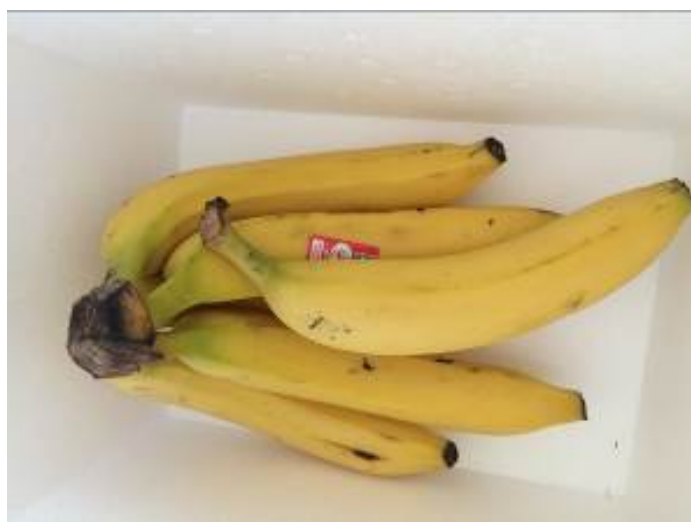

(a)

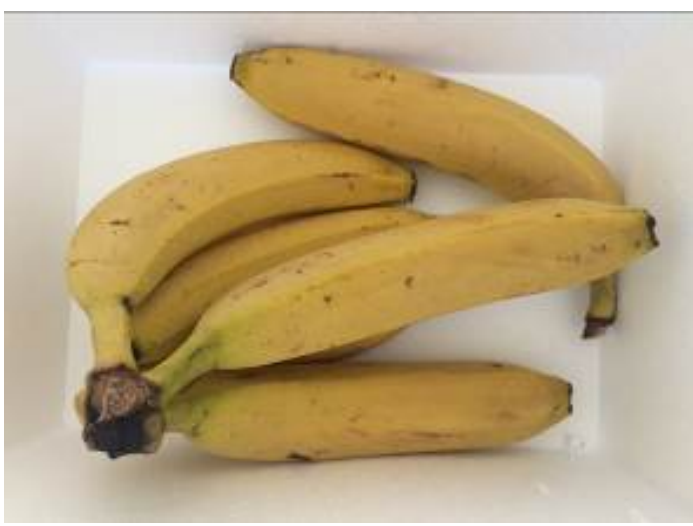

(b)

Figure 1. (a) Plátanos con índice de madurez tres almacenados en contenedores de poliestireno el día 06 de Marzo de 2015; (b) mismos frutos el día 10 del mismo mes.

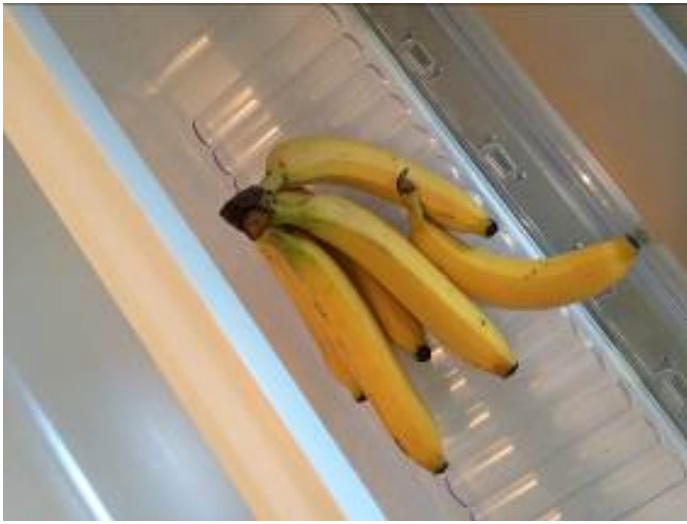

(a)

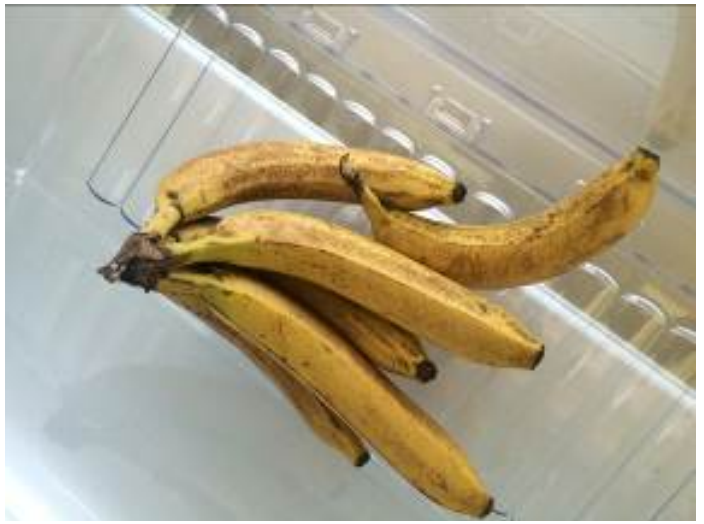

(b)

Figure 2. Plátanos (testigo) con índice de madurez tres almacenados en la bandeja inferior del refrigerador el día 06 de Marzo (a) y el día 10 (b) del mismo mes del 2015.

mismo periodo (6 - 10 de Marzo de 2015) se observó que los frutos presentaron de manera muy pronunciada los signos de madurez organoléptica o sensorial (manchas de color café en el pericarpio); sin embargo, a través del tacto y la presión manual se percibió que la firmeza de la pulpa de los frutos fue similar a la de aquéllos que fueron envasados en los contenedores de poliestireno. El sabor fue otra de las características similares a la de los frutos envasados en los contenedores mencionados. No obstante, el aspecto de los plátanos con manchas de color café en gran parte del pericarpio, seguramente en el mercado inhibiría su adquisición o compra por parte del consumidor.

En la Figure 3 se muestra como los plátanos con el índice de madurez dos que fueron almacenados en los contenedores de poliestireno, con temperatura de $10^{\circ} \mathrm{C}-12^{\circ} \mathrm{C}$ dentro del refrigerador y de $8^{\circ} \mathrm{C}-10^{\circ} \mathrm{C}$ dentro de los contenedores, tuvieron una vida de anaquel de 12 días hasta el 31 de Marzo, fecha en que presentaron el índice de madurez cuatro. Esto también confirma que en los plátanos confinados en este tipo de recipientes (atmósfera controlada) colocados dentro del refrigerador con ambiente frío, la respiración disminuyó y, como consecuencia de eso, también decreció la producción de etileno.

Sin embargo, en la Figure 4 se puede observar que cuando los plátanos fueron confinados en la bandeja inferior del refrigerador con temperatura de $10^{\circ} \mathrm{C}-12^{\circ} \mathrm{C}$, para el día 31 de Marzo de 2015 éstos presentaron pericarpio con manchas de color café, aunque con consistencia y sabor aceptables para su consumo.

Cuando los plátanos tuvieron el índice de madurez tres y el día 16 de Abril fueron almacenados en los contenedores de poliestireno dentro del refrigerador con las temperaturas antes mencionadas (Figure 5), éstos tardaron nueve días en presentar el índice de madurez cuatro, sin que en el epicarpio aparecieran los síntomas de madurez sensorial. De acuerdo con Wills et al. [28], se puede deducir que de los dos sistemas responsables de la síntesis del etileno, el sistema 1 inició la síntesis del etileno pero no logró desencadenar el funcionamiento del- 


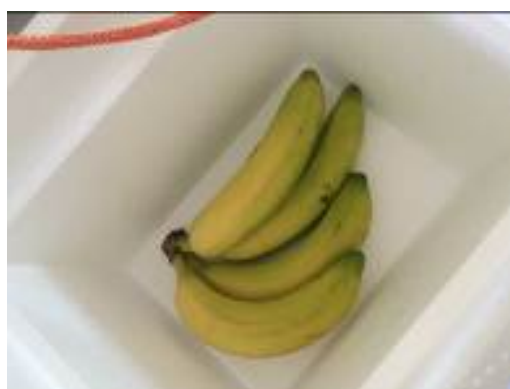

(a)

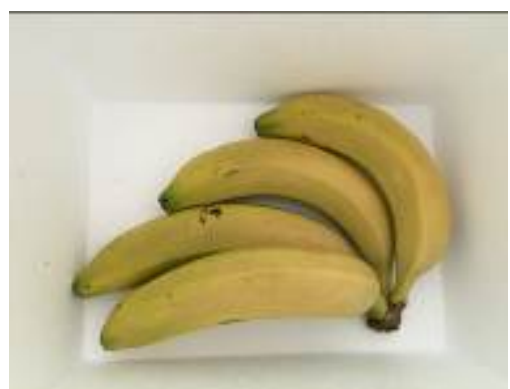

(b)

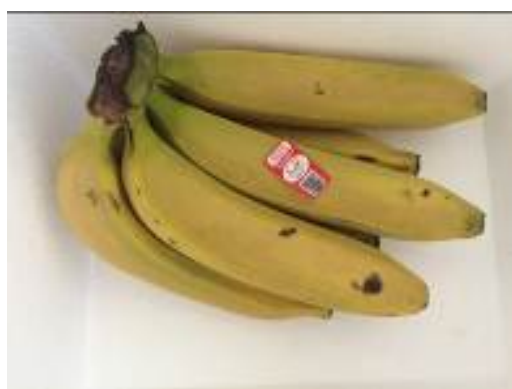

(c)

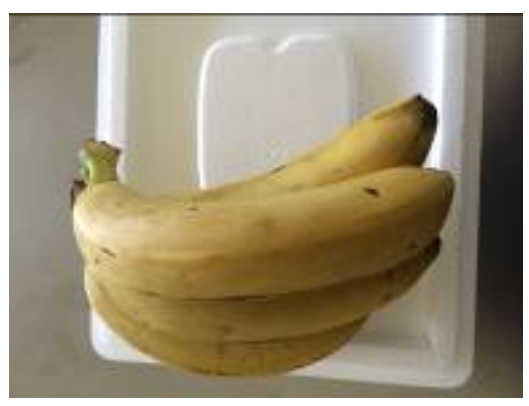

(d)

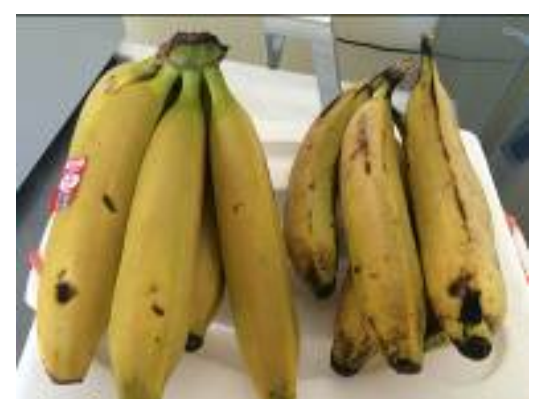

(e)

Figure 3. (a) Plátanos con índice de madurez dos que fueron almacenados el día 20 de Marzo de 2015 en contenedores de poliestireno; (b) mismos frutos el día 24; (c) día 30 y; (d) el día 31 y testigos al lado derecho) a los 30 días; (e) del mismo mes.

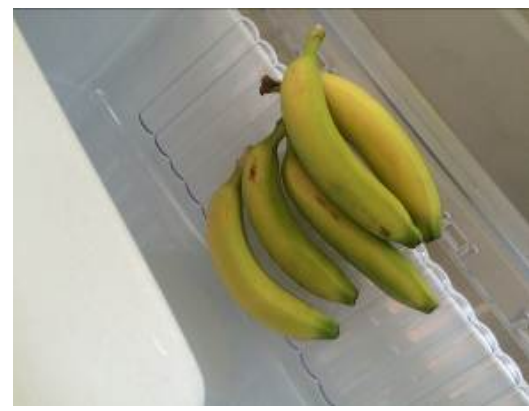

(a)

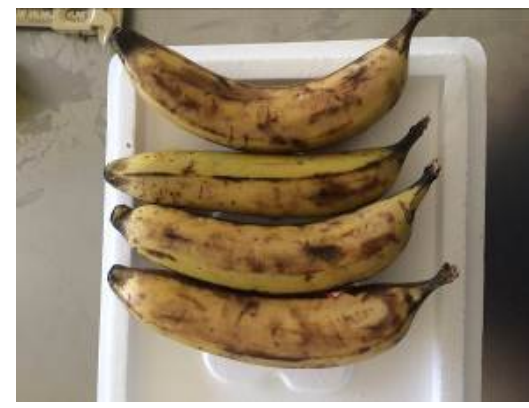

(b)

Figure 4. (a) Plátanos (testigo) con índice de madurez dos que fueron almacenados el día 20 de Marzo de 2015 en la charola inferior del refrigerador; (b) mismos frutos el día 31 de dicho mes.

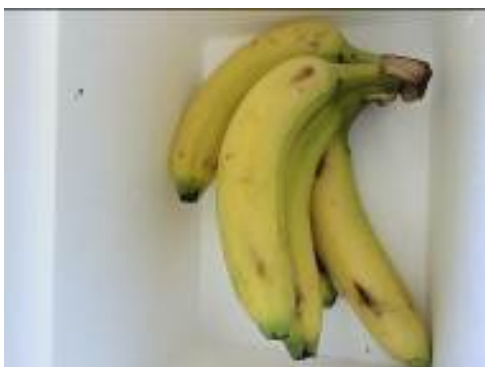

(a)

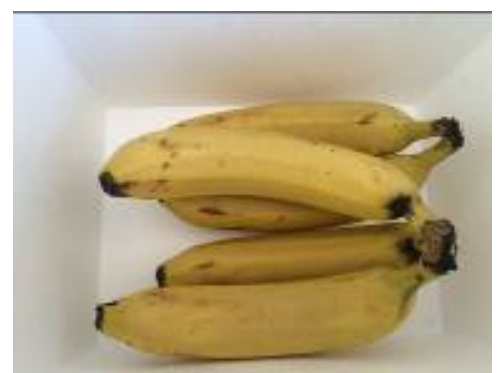

(b)

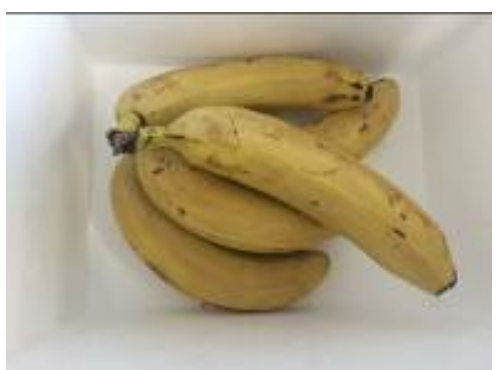

(c)

Figure 5. (a) Plátanos con índice de madurez tres almacenados en contenedores de poliestireno el día 16 de Abril; (b) mismos frutos el día 21 y; (c) el 24 de dicho mes del 2015.

sistema 2 para que ocurriera la síntesis de grandes cantidades de etileno necesarias para la plena integración de los procesos madurativos y aceleración de la madurez de los plátanos. 
A diferencia de lo observado en los plátanos embasados en los contenedores de poliestireno cerrados y misma temperatura dentro del refrigerador $\left(10^{\circ} \mathrm{C}-12^{\circ} \mathrm{C}\right)$, los frutos que fueron depositados en la bandeja inferior del refrigerador (testigos) presentaron los síntomas de madurez sensorial (manchas de color café en el epicarpio) a los seis días posteriores a su almacenamiento (Figure 6), lo que indica que, según Wills et al. [28], el sistema 1 desencadenó la síntesis de etileno en mayores cantidades que hicieron que los plátanos tuvieran un proceso de maduración más rápido en comparación a la que tuvieron en los contenedores de poliestireno cerrados.

Dentro de los contenedores de poliestireno cerrados con temperatura de $10^{\circ} \mathrm{C}-12^{\circ} \mathrm{C}$ en su interior, los plátanos con índice de madurez cuatro fueron almacenados y al cabo de 10 días después presentaron los síntomas de madurez sensorial o manchas de color café que se pueden observar en la Figure 7.

Contrariamente a lo sucedido con los plátanos dentro de los contenedores de poliestireno, en los testigos que fueron depositados en la bandeja inferior del refrigerador, a los diez días el epicarpio estuvo de color oscuro (Figure 8), lo que hizo que los plátanos ya no tuvieran buen aspecto para la comercialización.

En la Figure 9 se pueden apreciar los frutos con índice de madurez uno, los cuales también fueron almacenados dentro de los contenedores con $8^{\circ} \mathrm{C}-10^{\circ} \mathrm{C}$ de temperatura en su interior, y 21 días después alcanzaron el índice de madurez cuatro, haciéndose notorio que el sistema 1 de producción de etileno no desencadenó la generación de esta hormona en las grandes cantidades típicas del sistema 2, lo que de acuerdo con Wills et al. [28] retardó la maduración de los frutos.

En el Cuadro 1 se denota como el color, firmeza y sabor se van deteriorando conforme pasa el tiempo, y como los grados Brix se van incrementando de 26.1, 39.6 y 87.4\% al alcanzar los índices dos, tres y cuatro, respectiv-

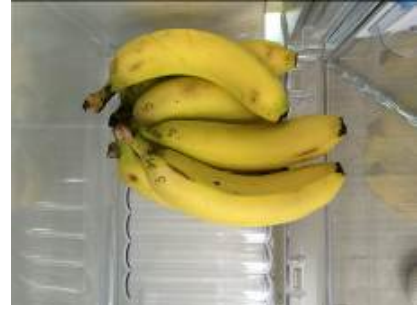

(a)

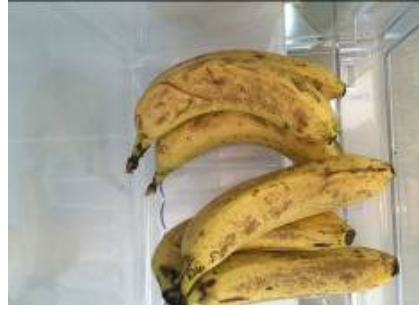

(b)

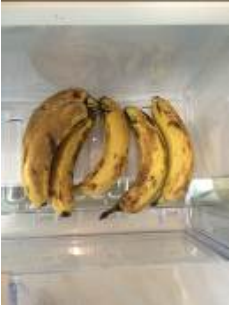

(c)

Figure 6. (a) Plátanos (testigo) con índice de tres, almacenados en la bandeja inferior del refrigerador el día 16 de Abril; (b) mismos frutos el 21 y; (c) el 24 del citado mes de 2015.

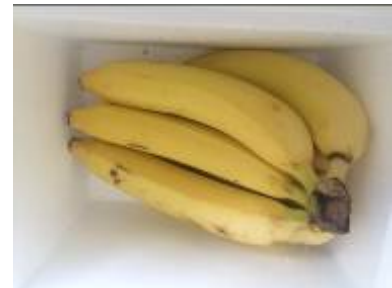

(a)

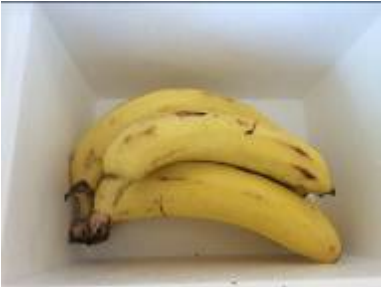

(b)

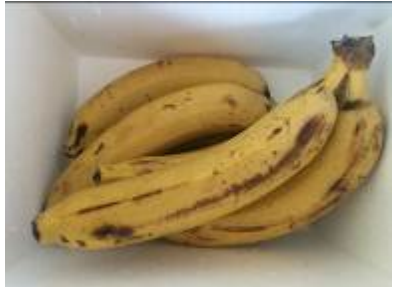

(c)

Figure 7. (a) Plátanos con índice de madurez cuatro almacenados en contenedores de poliestireno el día 11 de Mayo de 2015; (b) los mismos frutos hasta el día 13 y; (c) a los 20 días del mismo mes.

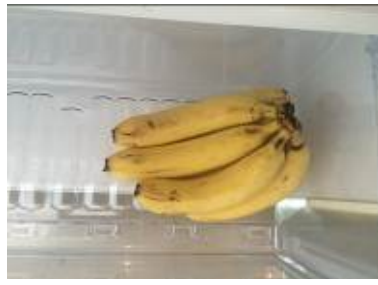

(a)

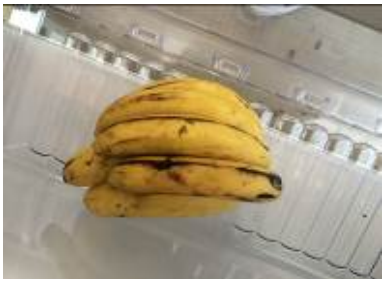

(b)

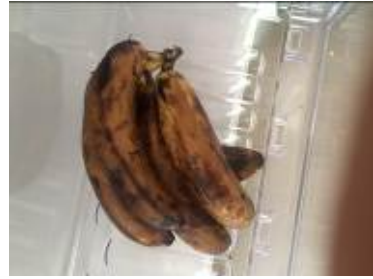

(c)

Figure 8. (a) plátanos (testigo) con índice de madurez cuatro almacenados en la bandeja inferior del refrigerador el día 11 de Mayo de 2015; (b) hasta el día 13 y; (c) a los 20 días de Mayo. 


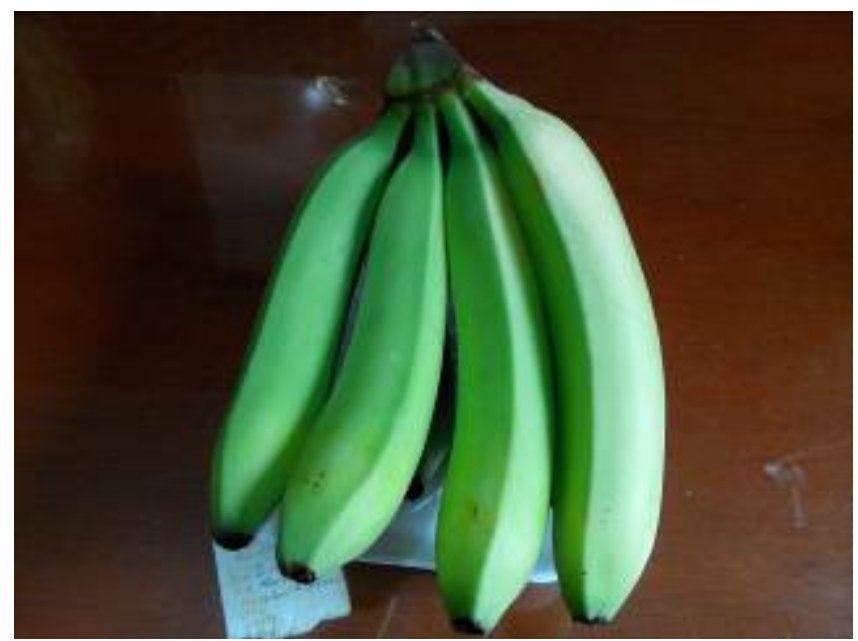

Figure 9. Plátanos con índice de madurez uno almacenados en contenedores de poliestireno cerrados colocados en el refrigerador el día 06 de Junio de 2015.

Cuadro 1. Características sensoriales en cuatro índices de madurez del plátano Cavendish Gigant (AAA).

\begin{tabular}{ccccc}
\hline Índice de madurez & Color & Firmeza & Sabor & Brix \\
\hline Índice 1 & $\mathrm{~V}$ & Fuerte & Insípido & $11.1 \mathrm{e}$ \\
Índice 2 & $\mathrm{VA}$ & Fuerte & Poco dulce & $14.0 \mathrm{~d}$ \\
Índice 3 & $\mathrm{APV}$ & Fuerte & Dulce & $15.5 \mathrm{~b}$ \\
Índice 4 & $\mathrm{AT}$ & Media & Dulce fuerte & $20.8 \mathrm{a}$ \\
Manchas café en cutícula & AC & Débil & Etanólico & $14.4 \mathrm{c}$ \\
DMSH & - & - & - & 0.24
\end{tabular}

Medias con letra diferente en la columna son estadísticamente diferentes (Tukey $\leq 0.05)$. V = verde, VA = verde amarillo, APV $=$ amarillo con pedúnculo verde, $\mathrm{AT}=$ amarillo total, $\mathrm{AC}$ = amarillo con manchas café.

amente, en comparación con el índice uno; pero mientras que al alcanzar el índice dos los plátanos superaron con $26.1 \%$ en grados Brix al promedio del índice uno (verde), los que alcanzaron el índice tres superaron en $10.7 \%$ a los del índice dos y los que llegaron al índice cuatro superaron en $34.2 \%$ a los del índice tres. No obstante, cuando los plátanos iniciaron a presentar manchas de color café sobre la cubierta, los grados Brix disminuyeron y los frutos ya presentaban condición etanólica o con cierta fermentación.

Los resultados en el cambio de color, firmeza, sabor y grados Brix debieron ser producto de fenómenos como la acción del etileno, la transpiración y la respiración, que aunque fueron disminuidas por las bajas temperaturas y la nula circulación de aire dentro de los recipientes de poliestireno cerrados, no dejaron de presentarse durante la vida de los plátanos.

\section{Conclusion}

La vida de anaquel de los plátanos se incrementó en los cuatro índices de madurez después que éstos fueron lavados con solución a $5.0 \mathrm{ppm}$ de hipoclorito de sodio y almacenados dentro de contenedores de poliestireno cerrados y colocados en cámara refrigerada con temperatura fresca, de tal manera que se cumple el principio de aislamiento térmico del poliestireno, por lo que éste se puede adicionar como una tecnología más en el procedimiento para incrementar la vida de anaquel del plátano.

\section{References}

[1] García, M.R., González M.M.F., García, S.R.C., Mora, F.J.S., González, E.A. and Martínez, D.A. (2013) El mercado del plátano (Musa paradisiaca) en México, 1971-2017. Agrociencia, 47, 399-410. 
[2] SIACON-SAGARPA (2006) Subsistema de Información Agrícola. Información de cultivos 1980-2005. CD Interactivo.

[3] Artés, F. (1995) Innovaciones de los tratamientos físicos modulados para preservar la calidad hortofrutícolas en la post-recolección. II. Tratamientos térmicos cíclicos. Revista Ciencia Tecnología de Alimentos, 35, 139-149.

[4] Artés, F. (1999) Avances en los tratamientos post-cosecha para la conservación en fresco de limón y pomelos. Levante Agrícola, Especial post-cosecha, 38, 348:289-294.

[5] Artés, F. (2000) Conservación de los productos vegetales en atmósferas odificadas. In: Lamúa, M., Ed., Aplicación del frío en los alimentos, Cap. 4, Mundi Prensa, 105-125.

[6] Parikh, H.R., Nair, G.M. and Modi, V.V. (1990) Some Structural Changes during Ripening of Mangoes (Mangifera indica var. Alphonso ) by Abscisic Acid Treatment. Annals of Botany, 65,121-127.

[7] Salisbury, F.B. and Ross, C.W. (2000) Fisiología de las Plantas. Paraninfo Thomson Learning, Madrid, 988 p.

[8] Artés, F. (1987) Refrigeración y comercialización hortofrutícolas en la Región de Murcia. II Edición, CEBAS-CSIC, $150 \mathrm{p}$.

[9] Martínez, J.J.M. (1997) La frigoconservación en naranjas y mandarinas. Rev. Phytoma, 90, 136-140.

[10] Vázquez, G.E., Ramírez, M.M., Mata, V.H., Araiza, F.R. and Alia, T.I. (2010) Atributos de calidad y vida de anaquel de frutos de cultivares de chile serrano en México. Revista Fitotecnia Mexicana, 33, 79-82.

[11] Guerra, F. (1996) Tecnología post-cosecha de frutos cítricos. Curso integral de citricultura. Instituto de Investigaciones de Fruticultura Tropical, 242-257.

[12] Ponce de León, L. and Bózquez, M.E. (1997) Técnicas de almacenamientos. Manejo post-cosecha del mango. Ed. EMEX. A. C., 22-24.

[13] Jiménez, C.M., Martínez, J.J.M. and Cuquerella, J. (1983) Plastic Individual Sear-Packaging of Spanish Fruit. XV International Congress of Refrigeration, Commission C2, 460-466.

[14] Martínez, A., Lee, R.A., Caparro, D. and Páramo, S. (2003) Postcosecha y Mercadeo de Hortalizas de Clima Frío Bajo Prácticas de Producción Sostenible. Fundación Universidad de Bogotá Jorge Tadeo Lozano, Bogotá, 58 p.

[15] Tuset, J.J. (1987) Podedumbres de los frutos cítricos. Generalitat Valenciano, Chancillería de Agricultura y Pesca. Valencia, Tomo 1, 206 p.

[16] Saucedo, C. and Arévalo, L. (1997) Fisiología y tecnología post-cosecha de mango. Memorias I Taller regional de manejo de productos de interés para el trópico. San José de Costa Rica, 1-10.

[17] Galán, S.V. (1999) Enfermedades, plagas y desórdenes no patogénicos del mango. El cultivo del mango. Ed. Mundi Prensa, 224-263.

[18] Tuset, J.J. (1999) Perspectiva del control de las podredumbres en la post-cosecha e cítricos. Levante Agrícola, Especial de Postcosecha, 272-280.

[19] Sheirs, J., Alexander, L. and Vainshtein, B. (2003) Modern Styrene Polymers. John Wiley and Sons, New York, 309.

[20] Perdomo, M.G.A. (2002) Plásticos y medio ambiente. Revista Iberoamericana, 3, 1-13.

[21] ANAPE (Asociación Nacional de Poliestireno Expandido) (2014) Proyecto ECO EPS para el Reciclado de envases y embalajes de poliestireno expandido usados. Proyecto ECO-EPS. http://www.anape.es/pdf/eco-eps.pdf

[22] Raimondo, E. and Espejo, C. (2002) Envases para frutas y hortalizas frescas. Revista de la Facultad de Ciencias Agrarias, 34, 93-97.

[23] Sisler, E.C. and Serek, M. (1997) Inhibitors of Ethylene Responses in Plants at the Receptor Level: Recent Developments. Physiologia Plantarum, 100, 577-582. http://dx.doi.org/10.1111/j.1399-3054.1997.tb03063.x

[24] Blankenship, S. (2001) Ethylene Effects and Benefits of 1-MCP. Perishables Handling Quarterly, 108, 2-4.

[25] Blankenship, S. and Dole, J. (2003) 1-Methylcyclopropene: A Review. Postharvest Biology and Technology, 28, 1-25. http://dx.doi.org/10.1016/S0925-5214(02)00246-6

[26] Osuna, G.J.A., Beltrán, J.A. and Urías, L.M. (2005) Efecto del 1-Metilciclopropeno (1-MCP) sobre la vida de anaquel y calidad de mango para exportación. Revista Fitotecnia Mexicana, 28, 271-278.

[27] García, A.E. (1988) Modificaciones al sistema de clasificación climática de Köppen. Instituto de Geografía, UNAM, México, 217 p.

[28] Wills, R., McGlasson, B., Graham, D. and Yoice, D. (1998) Introducción a la Fisiología y Manipulación Poscosecha de Frutas, Hortalizas y Plantas Ornamentales. $2^{\text {a }}$ Edición, Editorial Acribia, S. A., Zaragoza, 36-37. 